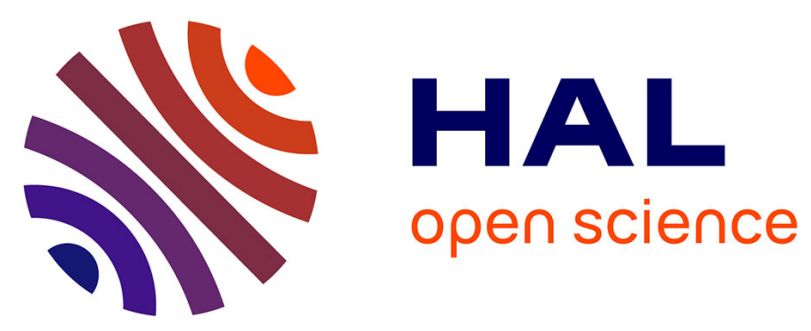

\title{
Signal-to-noise ratio in Terahertz wireless communication using field-effect-transistors as detectors
}

\author{
L. Tohme, S. Blin, P. Nouvel, A. Pénarier, J. Torres, L. Varani, Guillaume \\ Ducournau, Philippe Artillan, S. Bollaert, Yannick Roelens, et al.
}

\section{- To cite this version:}

L. Tohme, S. Blin, P. Nouvel, A. Pénarier, J. Torres, et al.. Signal-to-noise ratio in Terahertz wireless communication using field-effect-transistors as detectors. 2013 22ND INTERNATIONAL CONFERENCE ON NOISE AND FLUCTUATIONS (ICNF), Jun 2013, Montpellier, France. pp.1-3, 10.1109/ICNF.2013.6578992 . hal-00980298

\section{HAL Id: hal-00980298 \\ https://hal.science/hal-00980298}

Submitted on 21 Sep 2021

HAL is a multi-disciplinary open access archive for the deposit and dissemination of scientific research documents, whether they are published or not. The documents may come from teaching and research institutions in France or abroad, or from public or private research centers.
L'archive ouverte pluridisciplinaire HAL, est destinée au dépôt et à la diffusion de documents scientifiques de niveau recherche, publiés ou non, émanant des établissements d'enseignement et de recherche français ou étrangers, des laboratoires publics ou privés.

\section{(ㄷ)(i)}

Distributed under a Creative Commons Attribution| 4.0 International License 


\section{Signal-to-noise ratio in Terahertz wireless communication using field-effect-transistors as detectors}

\author{
L. Tohmé, S. Blin, P. Nouvel, \\ A. Pénarier, J. Torres and L. Varani \\ GIS Teralab, IES (UMR 5214), \\ CNRS-Université Montpellier 2, \\ 34095 Montpellier, France. \\ Email: lucie.tohme@ies.univ-montp2.fr
}

\author{
G. Ducournau, P. Artillan, \\ S. Bollaert and Y. Roelens \\ IEMN, UMR CNRS 8520, \\ Université de Lille 1, \\ 59652 Villeneuve dAscq, France.
}

\author{
D. Coquillat, D. But, \\ W. Knap and F. Teppe \\ GIS Teralab, L2C (UMR 5221), \\ CNRS-Université Montpellier 2, \\ 34095 Montpellier, France.
}

\begin{abstract}
We report on terahertz wireless communication experiments at $0.2 \mathrm{THz}$, using a commercial GaAs field-effecttransistor as detector. For the first time, we will present the transmission of pseudo-random bit sequence at $0.2 \mathrm{THz}$ using this commercial transistor and demonstrate open eye-patterns up to 1.5 Gbps. This transistor is integrated into a machined horn, so that its sensitivity is improved to $1 \mathrm{~V} / \mathrm{W}$, and has a $10 \mathrm{GHz}$ cut-off frequency. We will discuss signal-to-noise ratio in the terahertz wireless data transmission.
\end{abstract}

\section{INTRODUCTION}

Significative increase of bit data-rate in present wireless communication systems requires an increase of the carrier frequency. Wireless communication systems based on terahertz $(\mathrm{THz})$ carrier frequencies are interesting as allowing for datarates up to $100 \mathrm{Gbps}$. However, adequate $\mathrm{THz}$ sources and detectors are still under development [1]. Preliminary wireless communication systems have been successfully demonstrated mainly using Schottky barrier diodes as detectors [2]-[5]. At the moment, Schottky barrier diodes are by far the best detectors for communication, due to their high sensitivity $(10 \mathrm{kV} / \mathrm{W}$ at $0.3 \mathrm{THz})$ [3]. More recently, field-effect transistors (FETs) have also been demonstrated to be an alternative for low cost $\mathrm{THz}$ detection in wireless communication [6]. Detection by FETs can be very promising in comparison to existing detectors based on Schottky diodes as it is more easily compatible with integrated circuits such as demodulation circuits. The best reported performance of FETs detectors can achieve a responsivity up to few $\mathrm{kV} / \mathrm{W}$ at $0.3 \mathrm{THz}$ and a noise equivalent power in the range of a few $\mathrm{pW} / \mathrm{Hz}^{1 / 2}$ [7], [8]. These values are comparable to the best results reported for Schottky diode THz detectors, placing FETs as important competitors with the additional advantage of low resistance, easier integration as already mentioned, and relatively low price. In the real experimental conditions of $\mathrm{THz}$ wireless communication, signal-to-noise ratio is a combination of noises mainly due to amplifier and detrimental coupling signal at the modulation frequency.

In this paper, we propose to investigate the signal-tonoise ratio in communication systems based on FET detectors. Section 2 is devoted to the characterization of FET detectors, their integration, the determination of their sensitivity and bandwidth. In Section 3, we present experimental results of $\mathrm{THz}$ wireless communication with transmission of pseudorandom bit sequence using FET detector operating at room temperature, and show that the limitation is due to coupling through the gate and the source. Finally, we investigate some improvements and integration of the system for communication around $0.3 \mathrm{THz}$.

\section{FET DETECTOR CHARACTERIZATION}

As we mentioned earlier, our objective is to study the potential of commercial and low cost transistors operating at room temperature for the $\mathrm{THz}$ communication. For that purpose, we choose a pseudomorphic high-electron-mobility GaAs transistor (pHEMT) with a $200 \mathrm{~nm}$ gate length. Previous measurements have shown that these transistors are very sensitive to accidental external coupling through their gate and their source (ground coupling) [6]. Indeed, coupling through the gate induces amplification of the coupled signal. In order to protect the transistor from external coupling, we decide to place it in a guiding horn.

The wave-guide, set with a cut-off frequency of $0.174 \mathrm{THz}$, permits to realize a Faraday cage in order to block the major part of accidental coupling signals. The additional horn placed in front of the wave-guide, focuses the incoming $\mathrm{THz}$ radiation on the transistor, thus increasing its effective sensitivity. The latter ensures theoretical enhancement of 10 times for the detected signal at $0.3 \mathrm{THz}$. In this paper, all measurements considered have been realized using the transistor into the horn.

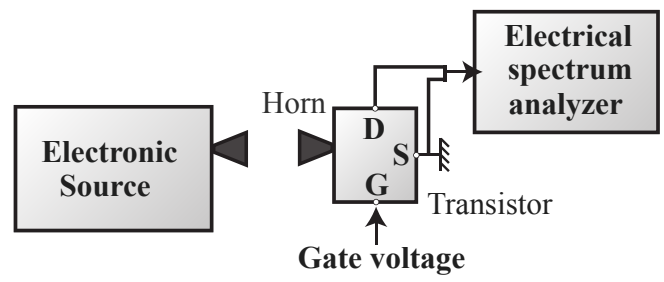

Fig. 1. Sensitivity characterization setup of pHEMT transistor. The transistor is placed respectively in front of $0.3 \mathrm{THz}$ and $0.65 \mathrm{THz}$ electronic $\mathrm{THz}$ tunable sources in order to measure sensitivity. 
1) Transistors sensitivity: A first experiment consists in measuring the GaAs pHEMT transistor sensitivity as a function of the $\mathrm{THz}$ frequency around $0.3 \mathrm{THz}$ and $0.65 \mathrm{THz}$. As shown in figure 1 , the setup for this sensitivity characterization consists of an electronic $\mathrm{THz}$ source and the transistor in the horn. The transistor is biased with an optimum gate-source voltage to increase its sensitivity and the rectified signal of the ac current induced by the incoming radiation is measured between drain and source with an electrical spectrum analyzer (ESA) [9]. To cover the large frequency domain, we use two electronic $\mathrm{THz}$ tunable sources: the frequency of the first one ranges from $0.22 \mathrm{THz}$ to $0.34 \mathrm{THz}$, while the second one ranges from $0.64 \mathrm{THz}$ to $0.69 \mathrm{THz}$. The power of both sources is around $1 \mathrm{~mW}$.

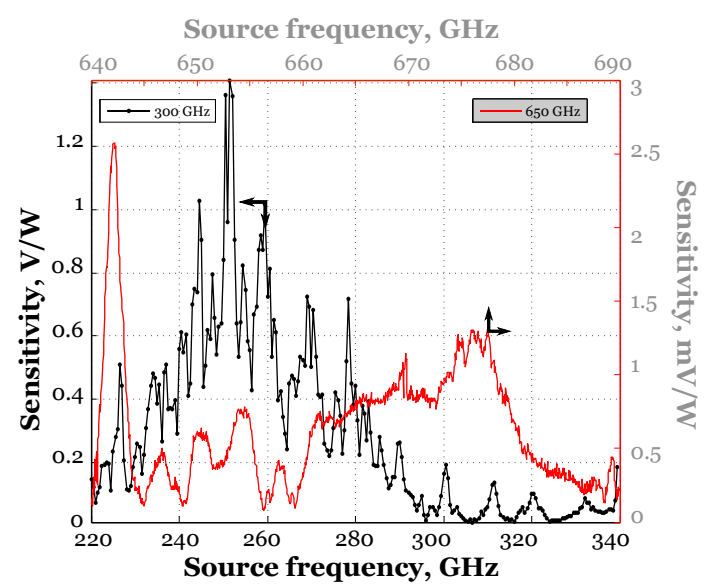

Fig. 2. Variation of the sensitivity, respectively at $0.3 \mathrm{THz}$ and $0.65 \mathrm{THz}$ of pHEMT transistor operating at room temperature. The response is quite flat on $30 \mathrm{GHz}$ between $0.24 \mathrm{THz}$ and $0.27 \mathrm{THz}$.

As can be seen in figure 2 , the transistor has a sensitivity of about $1 \mathrm{~V} / \mathrm{W}$ at $0.3 \mathrm{THz}$ and about $1 \mathrm{mV} / \mathrm{W}$ at $0.65 \mathrm{THz}$. We also point out that the response is quite flat over $30 \mathrm{GHz}$, between $0.24 \mathrm{THz}$ and $0.27 \mathrm{THz}$. These results suggest to use these transistors in $\mathrm{THz}$ communication systems.

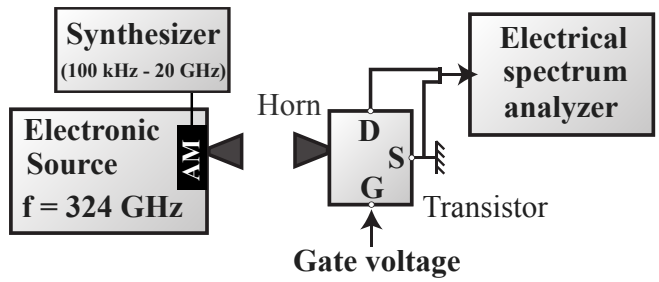

Fig. 3. Setup of detector bandwidth characterization. The pHEMT transistor with horn is placed in front of a $0.324 \mathrm{THz}$ source whose modulation frequency varies from $100 \mathrm{kHz}$ to $20 \mathrm{GHz}$, in order to determine the bandwidth of the detector.

2) Detector bandwidth measurement: A second experiment consists in measuring the detector bandwidth. In this study, we use an electronic $\mathrm{THz}$ source whose frequency is fixed at $0.324 \mathrm{THz}$, with an output power of about $1 \mathrm{~mW}$. We make the modulation frequency varying from $100 \mathrm{kHz}$ to $20 \mathrm{GHz}$ in order to determine the modulation bandwidth of the detector (figure 3). Again the transistor is biased with an optimum gatesource voltage.
Figure 4 illustrates the variation of the amplitude of the detected signal as a function of the modulation frequency. The red curve represents the signal and noise amplitude, and the black curve is the measurement of the noise alone, when an opaque screen is positioned between the source and the transistor. The noise is the result of the white noise of the ESA and the coupled signal via the transistor, and the measured one. Signal-to-noise ratio is about 20 to $30 \mathrm{~dB}$. This ratio can be improved by $15 \mathrm{~dB}$ when using an amplifier between the transistor drain and the ESA. We also notice that at $0.324 \mathrm{THz}$, we get a $10 \mathrm{GHz}$ bandwidth at detection, what is confirmed by the green curve, which represents a first-order low-pass fit using a $10 \mathrm{GHz}$ cut-off frequency.

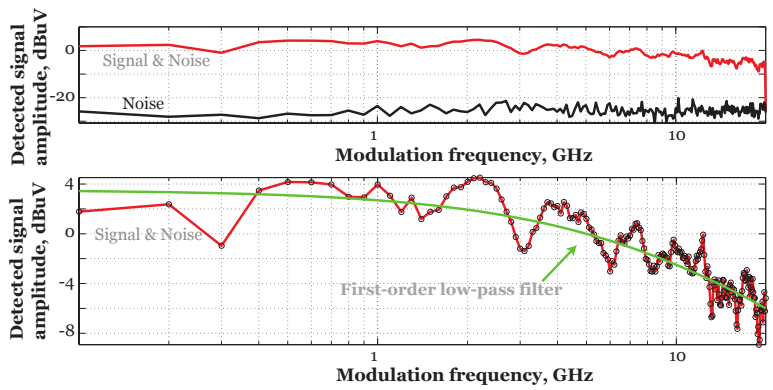

Fig. 4. Variation of the amplitude of the detected signal by the pHEMT transistor as a function of the modulation frequency. The first graph gives a signal-to-noise ratio of about 20 to $30 \mathrm{~dB}$ using a FSU 46 spectrum analyzer with a resolution bandwidth of $10 \mathrm{~Hz}$. The second graph illustrates a $10 \mathrm{GHz}$ bandwidth at $0.324 \mathrm{THz}$

\section{TERAHERTZ WIRELESS COMMUNICATION}

In this section, we discuss $\mathrm{THz}$ communication using the commercial pHEMT transistor in the horn, as well as the first transmission of pseudo-random bit sequence (PRBS). The experimental setup is presented in figure 5. The setup consists in a $0.2 \mathrm{THz}$ electronic source whose amplitude is modulated using a PRBS pattern generator. The output source power is around $2 \mathrm{~mW}$ (measured with calibrated pyroelectric sensor). The beam is collimated and focused by off-axis parabolic mirrors, after propagation of $20 \mathrm{~cm}$ and detected by the pHEMT transistor in the horn. The transistor is biased with a gate-source voltage of $-0.4 \mathrm{~V}$ to increase its sensitivity.

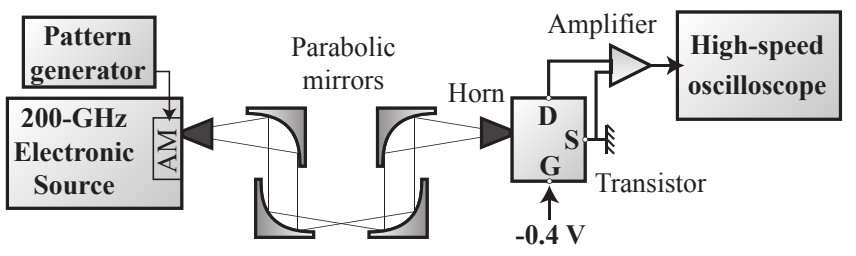

Fig. 5. Wireless communication setup. The $0.2 \mathrm{THz}$ electronic source is modulated using a PRBS pattern generator. Eye-patterns are observed on a high-speed oscilloscope at different data-rate frequencies.

The detected source-drain signal is amplified and observed on a high-speed oscilloscope. To evaluate the detected signal quality, eye-patterns are used and provide useful visual information when the data-rate frequency is varying and ensure the different amplifiers are operating properly. 
First, we use an amplifier with $200 \mathrm{MHz}$ bandwidth, $40 \mathrm{~dB}$ gain and $50 \mathrm{Ohm}$ input impedance. We make the datarate frequency varying and we observe eye-patterns with the oscilloscope. As shown in figure 6, the eye opening is still wide up to data-rates of $0.250 \mathrm{Gbps}$.

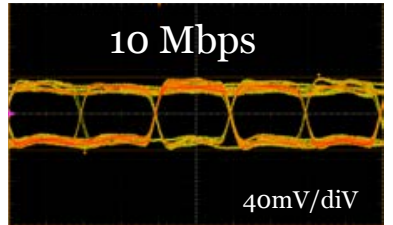

(a) (b)
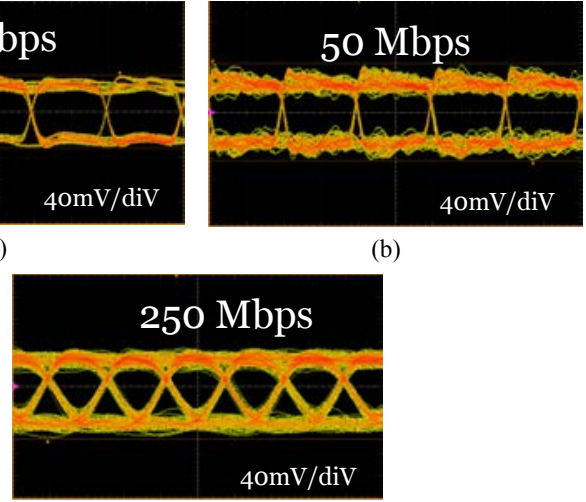

(c)

Fig. 6. Wide and high eye openings for three different data-rate frequencies of pseudo-random bit sequence: (a) $10 \mathrm{Mbps}$. (b) $50 \mathrm{Mbps}$. (c) $250 \mathrm{Mbps}$.

Using a $18 \mathrm{GHz}, 50 \mathrm{Ohms}$ amplifier, the data-rate was increased up to $1.5 \mathrm{Gbps}$, where the noise begins to degrade the eye-pattern (figure 7).

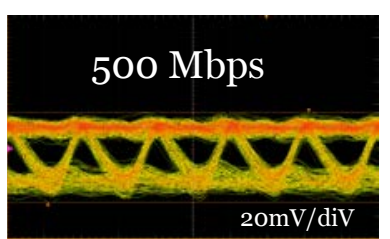

(a) (b)
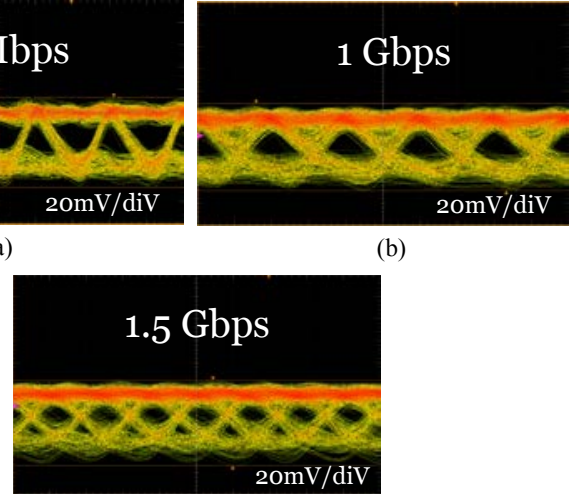

(c)

Fig. 7. Disrupted eye-pattern by direct coupling from the pattern generator through the gate supply for three different data-rate frequencies of pseudorandom bit sequence: (a) $500 \mathrm{Mbps}$. (b) $1 \mathrm{Gbps}$. (c) $1.5 \mathrm{Gbps}$.

We are working on optimized bias supply to reduce the coupled noise. In order to avoid this coupling, we will change gate supply from a source meter into an isolated battery, along with electronic devices for voltage adjustment.

\section{CONCLUSION}

As a summary, we have investigated the performances of a GaAs pHEMT commercial transistor as $\mathrm{THz}$ detector. This transistor has been integrated in a wave-guide module, and has a sensitivity of about $1 \mathrm{~V} / \mathrm{W}$ at $0.3 \mathrm{THz}$ and of about $1 \mathrm{mV} / \mathrm{W}$ at $0.65 \mathrm{THz}$, and a $10 \mathrm{GHz}$ modulation bandwidth at $0.324 \mathrm{THz}$ with a signal-to-noise ratio pf about $20 \mathrm{~dB}$. We have shown the importance of the integration of the commercial transistor into the guided horn, and high-data rate wireless communication was demonstrated for the first time using FETs as detectors at $0.2 \mathrm{THz}$. Data-rates up to $0.250 \mathrm{Gbps}$ were observed for the first time. As such data-rates are likely limited noise due to direct coupling, enhanced data-rates are expected in the very near future thanks to careful electromagnetic isolation.

\section{ACKNOWLEDGMENT}

This work was supported by ANR-JST project WITH "WIreless communication using TeraHertz plasmonic-nano ICT devices", by the GDR-I project "Semiconductor sources and detectors of $\mathrm{THz}$ frequencies" and by the Groupement d'Interêt Scientifique "Teralab". Authors thank the LanguedocRoussillon region through the "Terahertz Platform" and the "HERMES Platform". We also thank the IEMN facilities, partially supported by the "Contrat de Plan Etat Région" (CPER) and the Nord Pas-de-Calais region.

\section{REFERENCES}

[1] D. Dragoman and M. Dragoman, "Terahertz fields and applications," Progress in Quantum Electronics, vol. 28, no. 1, pp. 1-66, 2004.

[2] H. Song and T. Nagatsuma, "Present and future of terahertz communications," IEEE Transactions on Terahertz Science and Technology publication information, vol. 1, no. 1, pp. 256-263, 2011.

[3] C. Jastrow, K. Munter, R. Piesiewicz, T. Kurner, M. Koch, and T. KleineOstmann, "300 GHz transmission system," Electronics Letters, vol. 44, no. 3, pp. 213-214, 2008.

[4] L. Moeller, J. Federici, and K. Su, " $2.5 \mathrm{~Gb} / \mathrm{s}$ error-free transmission at $625 \mathrm{GHz}$ using a narrow-bandwidth $1 \mathrm{~mW}$ THz source," in 2011 XXXth URSI General Assembly and Scientific Symposium. IEEE, 2011, pp. $1-4$.

[5] L. Ishigaki, M. Shiraishi, S. Suzuki, M. Asada, N. Nishiyama, and $\mathrm{S}$. Arai, "Direct intensity modulation and wireless data transmission characteristics of terahertz-oscillating resonant tunneling diodes," Electronics Letters, vol. 48, no. 10, pp. 582-583, 2012.

[6] S. Blin, F. Teppe, L. Tohme, S. Hisatake, K. Arakawa, P. Nouvel, D. Coquillat, A. Pénarier, J. Torres, L. Varani, W. Knap, and T. Nagatsuma, "Plasma-Wave Detectors for TerahertzWireless Communication," IEEE Electron Device Letters, vol. 33, no. 10, pp. 1354-1356, 2012.

[7] F. Schuster, D. Coquillat, H. Videlier, M. Sakowicz, F. Teppe, L. Dussopt, B. Giffard, T. Skotnicki, and W. Knap, "Broadband terahertz imaging with highly sensitive silicon CMOS detectors," Optics Express, vol. 19, no. 8, pp. 7827-7832, 2011.

[8] E. Ojefors, U. Pfeiffer, A. Lisauskas, and H. Roskos, "A $0.65 \mathrm{THz}$ focal-plane array in a quarter-micron CMOS process technology," IEEE Journal of Solid-State Circuits, vol. 44, no. 7, pp. 1968-1976, 2009.

[9] M. Dyakonov, "Generation and detection of Terahertz radiation by field effect transistors," Comptes Rendus Physique, vol. 11, no. 7, pp. 413420, 2011. 